DOI: 10.20472/IAC.2019.052.011

CARL J. CASE

St. Bonaventure University, United States

DARWIN L. KING

St. Bonaventure University, United States

JULIE A. CASE

St. Bonaventure University, United States

\title{
PROFILING SOCIAL MEDIA USAGE AND TROLLING INCIDENCE: A GENDER EXAMINATION OF UNDERGRADUATE BUSINESS STUDENTS
}

\begin{abstract}
:
While social media participation continues to reach unprecedented levels, so has the incidence of online hate and harassment, also known as trolling. Because undergraduate business students will be the future users and managers of social media, this study was undertaken to empirically examine social media participation and trolling incidence by gender. Results demonstrate that although there are more than a dozen social media sites, undergraduates primarily use five sites. When comparing gender, females spent more minutes per day and had a higher subscription per site on nearly all study sites than males. In terms of trolling, while both genders received nearly the same volume of trolls per person, a larger percentage of males versus females were trolled in nearly all the study sites. Overall, findings suggest that gender is a factor both with respect to social media participation and trolling incidence.
\end{abstract}

\section{Keywords:}

Trolling, Social Media Usage, Empirical Study, Online Behavior, Gender, Business Students 


\section{Introduction}

Social media participation has reached extraordinary levels, especially regarding younger individuals. In February of 2017, for example, Facebook achieved the level of 2.3 billion monthly active users and had 950 million average hours per day spent on Facebook services (Lazarus, 2019; Edwards, 2018). In June of 2018, Instagram surpassed one billion active monthly users (Statista,2019). In October of 2018, Twitter had 326 million active monthly users and 500 million daily tweets (Aslam, 2019). This included $24 \%$ of all Internet male and $21 \%$ of all Internet female users with $37 \%$ of users between the ages of 18 and 29 years old. Also, in 2018, eMarketer estimated that nearly 85 million individuals, or $25 \%$ of the population in the U.S., used Snapchat, a $7.1 \%$ increase from 2017 with over 16 million of these users age 12 to 17 years old (Kats, 2018). In February of 2019, there were over 1.9 billion logged-in users visiting YouTube each month and over a billion hours of video viewed each day (YouTube, 2019). Sixty-two percent of these users were male and 38\% were female with 34\% of users between the ages of 18 and 34 years old (Merchdope, 2019).

In concert with this growth, however, have been a variety of troubling behaviors. In 2018, for instance, it was learned that Facebook made 87 million users' data available without permission to Cambridge Analytica for political purposes, had 29 million users' information including birthdate and phone numbers hacked, and shared user data without permission with business partners (Lazarus, 2019). As a likely consequence, Facebook stock fell $5 \%$ in the three weeks following the Cambridge Analytica revelations (Kirkpatrick, 2018).

In addition, Twitter suspended 70 million accounts during May and June 2018 to improve information quality such as countering trolling, fake accounts, bots, disinformation, and other malicious occurrences (Ortutay \& Sweet, 2018). The non-profit Knight Foundation, however, found that more than $80 \%$ of the accounts, primarily run by foreign entities, used to circulate misinformation for the 2016 U.S. election continued to publish more than one million tweets per day in 2018 (Schladebeck, 2018).

One particularly insidious problem is that of trolling. The Merriam-Webster dictionary defines trolling as "to antagonize (others) online by deliberately posting inflammatory, irrelevant, or offensive comments or other disruptive content" (2019). A 2018 Anti-Defamation League study, for example, found that $37 \%$ of Americans were subjected to severe hate and harassment online, up from 18\% in 2017 (Shieber, 2019). This is disturbing given that in 2018, Americans spent 24 hours per week online (Steinmetz, 2018). Of note, 56\% of Facebook, 19\% of Twitter, 17\% of YouTube, and $16 \%$ of Instagram users indicated being cyberbullied. As a result, $38 \%$ of respondents stopped, reduced, or changed online activities and $15 \%$ took steps to reduce risks to his/her physical safety.

Previous research studies have examined factors related to trolls such as who are trolls, why do they troll, what are the trigger mechanisms, and so on. This study, on the other hand, was conducted to empirically profile social media usage and troll victimization by gender. Undergraduate business students were selected as subjects because current business students are the future professionals that will be utilizing social media in business. Ultimately, these findings will be helpful in determining if students are adequately prepared to face these 
challenges when they enter the corporate workforce. This research was conducted to examine several questions. With respect to gender, what are the primary social media sites utilized and the incidence of trolling within each site both in terms of the percent of students and volume of trolls? Are there relationships between the factors of gender, time spent on social networking, and the volume of trolls received?

\section{Previous Research}

As a baseline to better understand undergraduate business student online behavior, the authors conducted an exploratory study (Case and King, 2017). Results showed that all students indicated using at least one social media site with the average undergraduate spending 176 minutes (nearly 3 hours) per day on social media sites. Although undergraduate business students used nearly 20 social media sites, there were five sites that were used by most students. These include Snapchat (95\% of students), Instagram (88\% of students), Facebook (81\% of students), Twitter (76\% of students), and YouTube (67\% of students). Relative to trolling, the highest percentage of site users being trolled included YikYak (63\% of users) and Twitter (32\% of users). The social media sites that other individuals were most actively trolled included 4chan (100\% of respondents), YikYak (75\% of respondents), Twitter ( $67 \%$ of respondents), Facebook (64\% of respondents), Reddit (64\% of respondents), Tumblr (57\% of respondents), and Instagram (49\% of respondents). Overall, $41 \%$ of students reported being trolled and $73 \%$ indicated noticing others being trolled at least once during the past six months. In terms of volume, on average, a student was trolled more than one time per month (8 times per student during the prior six months) and each student reported seeing an average of 37 trolls per month (223 during the past six months) of others being trolled.

Previous research studies have also examined trolling. Researchers have conducted studies that relate to retweeting, motivators to troll, trigger mechanisms, and characteristics of trolls.

Relative to tweeting, Brady, et.al, (2017) found that tweets containing strong and emotional language, or moral outrage, are more likely to be retweeted. Using a sample of 563,312 social media communications about three polarizing moral/political issues, the researchers observed that the presence of moral-emotional words in messages increased their diffusion by a factor of $20 \%$ for each additional word. Furthermore, moral contagion was bounded by group membership, in other words, moral-emotional language increased diffusion more strongly within liberal and conservative networks, and less between them.

In terms of why trolls troll, semi-structured interviews with 22 self-confessed trolls found that there are a variety of behaviors trolls consider trolling (Cook, Schaafsma, \& Antheunis, 2017). Three key motivations to troll emerged: personal enjoyment, revenge, and thrill-seeking. Trolling also appeared to be a cyclical, self-perpetuating phenomenon enabled by the online community at large.

Regarding triggers, Cheng, et.al, (2017) explored two primary trigger mechanisms to trolling behavior: the individual's mood and the surrounding context of a discussion (e.g., exposure to prior trolling behavior). Through the use of an experiment simulating an online discussion, the researchers found that both negative mood and seeing troll posts by others significantly increased the probability of a user trolling, and together doubled this probability. The study was 
subsequently extended via a data-driven, longitudinal analysis of a large online news discussion community. This analysis revealed a predictive model of trolling behavior suggesting that mood and discussion context together can explain trolling behavior better than an individual's history of trolling. Overall, results suggest that ordinary people can, under the right circumstances, behave like trolls.

Finally, the characteristics of trolls have been examined. An online study of 417 individuals found that men were more likely than women to engage in trolling and higher levels of trait psychopathy and sadism predicted trolling behavior (Sest and March, 2017). Lower levels of affective empathy predicted perpetration of trolling and trait psychopathy moderated the association between cognitive empathy and trolling. Results indicated that when high on trait psychopathy, trolls employ an empathic strategy of predicting and recognizing the emotional suffering of their victims, while abstaining from the experience of these negative emotions. Thus, trolls appear to be master manipulators of both cyber-settings and their victims' emotions. Overall, individuals with high levels of cognitive empathy and psychopathic traits were more likely to troll. In other words, their high level of cognitive empathy indicates they are very good at understanding what hurts people and their high level of psychopathy means they simply do not care.

\section{Research Design}

This study employs a survey research design. The research was conducted at a private, northeastern U.S. university. A Student Social Media Usage and Troll Incidence instrument was developed by the authors and administered to undergraduate students enrolled in a School of Business course. The courses included a variety of subjects such as Business Information Systems, Introduction to Financial Accounting, Introduction to Marketing, Macroeconomics, and Business Policy. A convenience sample of class sections and faculty members was selected. The surveys were collected each semester during a three-year, five-consecutive semester period (from Fall 2016 through Fall 2018) in academic classrooms. To ensure consistency, the same questions were asked during each of the semesters.

The survey instrument was utilized to collect student demographic data such as gender and academic class. In addition, the survey examined student Internet behavior regarding online social media sites. Students were asked to estimate the average number of minutes spent daily on fourteen social media sites and list any other social networking sites used by the student. Moreover, students were prompted to estimate the number of times that he/she had been trolled on each site during the past six months. Results were summarized by social media site and correlations were calculated to determine potential relationships between the study factors of gender, social media usage minutes, and the quantity of trolling incidences.

Because of the sensitivity of the subject and to encourage honesty, no personally-identifiable data were collected and respondents were informed that surveys were anonymous, participation was voluntary, and responses would have no effect on his/her course grade. As a result, the response rate was nearly 100 percent. 


\section{Results}

A sample of 927 usable surveys was obtained. Table 1 indicates that $65 \%$ of the respondents were male and $35 \%$ were female.

\section{Table 1: Gender Response Rate}

\begin{tabular}{||l|r||}
\hline & Total \\
\hline \hline Male & $65 \%$ \\
\hline Female & $35 \%$ \\
\hline Count & 927 \\
\hline
\end{tabular}

Source: Own based upon survey data

The response rate by academic class was relatively equally distributed. Table 2 illustrates that $17 \%$ of respondents were freshmen, $33 \%$ were sophomores, $21 \%$ were juniors, and $29 \%$ were seniors.

\section{Table 2: Academic Class Response Rate}

\begin{tabular}{|c|c|}
\hline & Total \\
\hline Freshmen & $17 \%$ \\
\hline Sophomore & $33 \%$ \\
\hline Junior & $21 \%$ \\
\hline Senior & $29 \%$ \\
\hline
\end{tabular}

Responses were first examined with respect to the percentage of students using the various social media sites per semester. Although 14 sites were provided on the survey instrument, each respondent was prompted to list any "other" social media sites that he/she utilized. The "other" sites named included Barstool, GroupMe, Tinder, Trello, Twitch, VSCO, Wall Street Oasis, and WhatsApp. Table 3 illustrates that with respect to males, the most subscribed sites included Snapchat (92\% of males), Instagram (86\%), Facebook $(71 \%)$, Twitter $(77 \%)$, and YouTube (77\%). Lesser subscribed sites included Linkedln (30\% of males), Reddit (11\%), Google+ (8\%), Pinterest (4\%), Tumblr (3\%), Other (3\%), YikYak (2\%), 4chan (1\%), 8chan (0\%), and Voat (0\%). With respect to females, the most subscribed sites included Instagram (95\% of females), Snapchat (94\%), Facebook (88\%), Twitter (78\%), and YouTube (61\%). Lesser subscribed sites 
included Pinterest (44\%), Linkedln (34\% of females), Google+ (17\%), Tumblr (8\%), Reddit (2\%), YikYak $(2 \%)$, Other $(2 \%)$, 4chan $(0 \%)$, 8chan $(0 \%)$, and Voat $(0 \%)$. A larger percentage of females (versus males) used Snapchat, Instagram, Facebook, Twitter, Linkedln, Pinterest, Google+, and Tumblr while a larger percentage of males used YouTube, Reddit, Other, and 4chan. Overall, nearly all respondents indicated using at least one social media site during the previous six months.

\section{Table 3: Percent of Students Using Social Media by Gender}

\begin{tabular}{|c|c|c|c|}
\hline Social Media Site & Male & Female & Overall \\
\hline Snapchat & $92 \%$ & $94 \%$ & $93 \%$ \\
\hline Instagram & $86 \%$ & $95 \%$ & $89 \%$ \\
\hline Facebook & $71 \%$ & $88 \%$ & $77 \%$ \\
\hline Twitter & $77 \%$ & $78 \%$ & $77 \%$ \\
\hline YouTube & $77 \%$ & $61 \%$ & $71 \%$ \\
\hline Linkedln & $30 \%$ & $34 \%$ & $31 \%$ \\
\hline Pinterest & $4 \%$ & $44 \%$ & $18 \%$ \\
\hline Google+ & $8 \%$ & $17 \%$ & $11 \%$ \\
\hline Reddit & $11 \%$ & $2 \%$ & $8 \%$ \\
\hline Tumblr & $3 \%$ & $8 \%$ & $5 \%$ \\
\hline YikYak & $2 \%$ & $2 \%$ & $2 \%$ \\
\hline Other & $3 \%$ & $2 \%$ & $2 \%$ \\
\hline 4chan & $1 \%$ & $0 \%$ & $1 \%$ \\
\hline 8chan & $0 \%$ & $0 \%$ & $0 \%$ \\
\hline Voat & $0 \%$ & $0 \%$ & $0 \%$ \\
\hline Overall Average & $99 \%$ & $100 \%$ & \\
\hline
\end{tabular}

Source: Own based upon survey data

Table 4 presents, with respect to those that used a given site, the volume of minutes per day that a student indicated he/she used each social media site. With respect to males, respondents indicated spending 60 minutes on 8chan, 56 minutes on Other, 55 minutes on 4chan, 51 minutes 
per day on Snapchat, 46 minutes on Twitter, 46 minutes on YouTube, 44 minutes on Instagram, 37 minutes on Google+, 34 minutes on Reddit, 27 minutes on Facebook, 24 minutes on Pinterest, 17 minutes on Tumblr, 14 minutes on Linkedln, and 7 minutes on YikYak. Females indicated spending 60 minutes on Reddit, 56 minutes per day on Snapchat, 52 minutes on Instagram, 48 minutes on Other, 47 minutes on Twitter, 40 minutes on Facebook, 37 minutes on YouTube, 28 minutes on YikYak, 25 minutes on Pinterest, 22 minutes on Google+, 14 minutes on Tumblr, and 11 minutes on Linkedln. Females (versus males) spent more time each day using Snapchat, Instagram, Facebook, Twitter, Pinterest, Reddit, and YikYak while males spent more time using YouTube, Linkedln, Google+, Tumblr, Other, 4chan, and 8chan. Overall, females indicated spending 215 minutes (more than 3 hours), or 27 more minutes than males, each day using social media.

Table 4 : Minutes Per Day Utilizing Social Media by Gender

\begin{tabular}{|c|c|c|c|}
\hline Social Media Site & Male & Female & $\begin{array}{c}\text { Minutes } \\
\text { Difference }\end{array}$ \\
\hline Snapchat & 51 & 56 & 5 \\
\hline Instagram & 44 & 52 & 8 \\
\hline Facebook & 27 & 40 & 13 \\
\hline Twitter & 46 & 47 & 1 \\
\hline YouTube & 46 & 37 & -9 \\
\hline Linkedln & 14 & 11 & -3 \\
\hline Pinterest & 24 & 25 & 1 \\
\hline Google+ & 37 & 22 & -15 \\
\hline Reddit & 34 & 60 & 26 \\
\hline Tumblr & 17 & 14 & -3 \\
\hline YikYak & 7 & 28 & 21 \\
\hline Other & 56 & 48 & -8 \\
\hline 4chan & 55 & 0 & -55 \\
\hline 8chan & 60 & 0 & -60 \\
\hline Voat & 0 & 0 & 0 \\
\hline Overall Average & 188 & 215 & 27 \\
\hline
\end{tabular}

Source: Own based upon survey data 
Next, the percentage of students receiving trolls at each social media site was examined by gender (Table 5). With respect to males, the sites with the highest percentage of site users being trolled included 8 chan (50\% of users), Voat (50\% of users), YikYak ( $47 \%$ of users), 4chan (33\% of users), and Twitter (29\% of users). Lesser trolled sites included Other (21\% of users), Instagram (20\% of users), Snapchat (17\% of users), Reddit (16\% of users), and Facebook (15\% of users). The least trolled sites included Pinterest ( $8 \%$ of users), Tumblr ( $6 \%$ of users), Google+ ( $6 \%$ of users), YouTube ( $5 \%$ of users), and Linkedln ( $2 \%$ of users). With respect to females, the site with the highest percentage of site users being trolled was YikYak (60\% of users). Lesser trolled sites included Twitter (17\% of users), Other (13\% of users), Instagram (12\% of users), Snapchat ( $11 \%$ of users), and Facebook (11\% of users). The least trolled sites included Linkedln ( $4 \%$ of users), Tumblr ( $4 \%$ of users), YouTube (3\% of users), Pinterest ( $2 \%$ of users), Google+ ( $2 \%$ of users), Reddit ( $0 \%$ of users), 4 chan ( $0 \%$ of users), 8 chan ( $0 \%$ of users), and Voat ( $0 \%$ of users). Overall, $40 \%$ of males and $26 \%$ of females reported being trolled.

\section{Table 5: Percent of Students Trolled by Gender}

\begin{tabular}{|c|c|c|c|}
\hline Social Media Site & Male & Female & $\begin{array}{c}\text { Percent } \\
\text { Difference }\end{array}$ \\
\hline Snapchat & $17 \%$ & $11 \%$ & -6 \\
\hline Instagram & $20 \%$ & $12 \%$ & -8 \\
\hline Facebook & $15 \%$ & $11 \%$ & $\overline{-4}$ \\
\hline Twitter & $29 \%$ & $17 \%$ & -12 \\
\hline YouTube & $5 \%$ & $3 \%$ & -2 \\
\hline Linkedln & $2 \%$ & $4 \%$ & 2 \\
\hline Pinterest & $8 \%$ & $2 \%$ & -6 \\
\hline Google+ & $6 \%$ & $2 \%$ & $\overline{-4}$ \\
\hline Reddit & $16 \%$ & $0 \%$ & -16 \\
\hline Tumblr & $6 \%$ & $4 \%$ & -2 \\
\hline YikYak & $47 \%$ & $60 \%$ & 13 \\
\hline Other & $21 \%$ & $13 \%$ & -8 \\
\hline 4chan & $33 \%$ & $0 \%$ & -33 \\
\hline 8chan & $50 \%$ & $0 \%$ & -50 \\
\hline Voat & $50 \%$ & $0 \%$ & -50 \\
\hline
\end{tabular}




\begin{tabular}{||c|r|r|r||}
\hline Social Media Site & Male & Female & $\begin{array}{c}\text { Percent } \\
\text { Difference }\end{array}$ \\
\hline \hline Overall Average & $40 \%$ & $26 \%$ & -14 \\
\hline
\end{tabular}

Source: Own based upon survey data

The quantity of trolls received for only those individuals that were trolled is presented in Table 6 . With respect to males, the most to least actively trolled incidences were 4chan (66.7 incidences per user during a semester), Reddit (16.3), Snapchat (9.0), YouTube (6.4), Instagram (6.1), Twitter (6.1), Facebook (5.0), Other (3.0), Linkedln (2.0), Pinterest (2.0), Google+ (1.7), YikYak (1.1), Tumblr (0), 8chan (0), and Voat (0). With respect to females, activity included other (100 incidences per user during a semester), YikYak (36.7), Pinterest (19.0), YouTube (16.3), Google+ (10.0), Facebook (9.4), Linkedln (8.0), Snapchat (7.4), Twitter (7.3), Tumblr (5.0), Instagram (4.9), Reddit (0), 4chan (0), 8chan (0), and Voat (0). Overall, the number of incidences per student was nearly identical for males and females, 17.8 and 17.7 , respectively.

Table 6: Quantity of Trolls for Only Students Trolled by Gender

\begin{tabular}{||l|r|r|r||}
\hline \hline Social Media Site & \multicolumn{1}{|c|}{ Male } & \multicolumn{1}{|c||}{ Female } & \multicolumn{1}{|c||}{$\begin{array}{c}\text { Quantity } \\
\text { Difference }\end{array}$} \\
\hline \hline Snapchat & 9.0 & 7.4 & -1.6 \\
\hline Instagram & 6.1 & 4.9 & -1.2 \\
\hline Facebook & 5.0 & 9.4 & 4.4 \\
\hline Twitter & 6.1 & 7.3 & 1.2 \\
\hline YouTube & 6.4 & 16.3 & 9.9 \\
\hline Linkedln & 2.0 & 8.0 & 6.0 \\
\hline Pinterest & 2.0 & 19.0 & 17.0 \\
\hline Google+ & 1.7 & 10.0 & 8.3 \\
\hline Reddit & 16.3 & 0.0 & -16.3 \\
\hline Tumblr & 0.0 & 5.0 & 5.0 \\
\hline YikYak & 1.1 & 36.7 & 35.6 \\
\hline Other & 3.0 & 100.0 & 97.0 \\
\hline 4chan & 66.7 & 0.0 & -66.7 \\
\hline
\end{tabular}




\begin{tabular}{||l|r|r|r||}
\hline Social Media Site & \multicolumn{1}{|c|}{ Male } & Female & $\begin{array}{c}\text { Quantity } \\
\text { Difference }\end{array}$ \\
\hline \hline 8chan & 0.0 & 0.0 & 0.0 \\
\hline Voat & 0.0 & 0.0 & 0.0 \\
\hline Overall Average & 17.8 & 17.7 & -0.1 \\
\hline
\end{tabular}

Source: Own based upon survey data

Finally, Spearman Rho correlations were calculated to determine if there were correlations between the study factors of gender, troll volume, and social media usage minutes. As indicated in Table 7, user minutes spent using social media and troll volume each had a statistically significant correlation (significant at the .01 level) to gender. In other words, females were more likely to spend more time on social media and males were more likely to be trolled. Moreover, the more time spent on social media increased the likelihood of being trolled in general.

\section{Table 7: Spearman Rho Correlations Between Study Factors}

\begin{tabular}{||l|l|l||}
\hline Study Factor & Gender & $\begin{array}{l}\text { Troll } \\
\text { Volume }\end{array}$ \\
\hline \hline Minutes Using Social Media & $-.132^{\star *}$ & $.090^{\star *}$ \\
\hline Troll Volume & $.135^{\star \star}$ & \\
\hline
\end{tabular}

Source: Own based upon survey data

${ }^{*}$ Correlation is significant at .05 level (2-tailed).

${ }^{* *}$ Correlation is significant at .01 level (2-tailed).

\section{Conclusions}

Results illustrate that for both genders, there are five sites that were used by most students. These include Snapchat (93\% of students), Instagram (89\% of students), Facebook (77\% of students), Twitter (77\% of students), and YouTube (71\% of students). Linkedln and Pinterest were used by considerably less students, $31 \%$ and $18 \%$, respectively. The remaining sites were not commonly used by undergraduates. The least utilized social media sites were Google+ $(11 \%$ of students), Reddit ( $8 \%$ of students), Tumblr ( $5 \%$ of students), YikYak ( $2 \%$ of students), Other ( $2 \%$ of students), 4chan (1\% of students), 8chan ( $0 \%$ of students), and Voat ( $0 \%$ of students). Overall, nearly $100 \%$ of students indicated using social media. When comparing gender, although participation varied by social media site, a larger percentage of females versus males subscribed to each of the social media sites except YouTube and Reddit. Moreover, Instagram had the highest percentage (95\%) of female users and Snapchat had the highest percentage $(92 \%)$ of male users. 
The time spent using social media varied by gender with females spending 5 more minutes per day on Snapchat, 8 more minutes per day on Instagram, 13 more minutes per day on Facebook, 1 more minute per day on Twitter, 1 more minute per day on Pinterest, 26 more minutes per day on Reddit, and 21 more minutes per day on YikYak than males. Males spent 9 more minutes on YouTube, 3 more minutes on Linkedln, 15 more minutes on Google+, 3 more minutes of Tumblr, 8 more minutes on Other, 55 more minutes on 4chan, and 60 more minutes on 8chan than females. Overall, males spent 188 minutes and females spent 215 minutes on social media per day. Thus, females spent 27 more minutes or $14 \%$ more time than males. Moreover, of the 5 primary sites used by students, females versus males spent more time on each of the sites except YouTube.

An examination of trolling found that in terms of the percent of students by gender that were trolled in the five primarily used sites, $11 \%$ of females and $17 \%$ of males were trolled in Snapchat, $12 \%$ of females and $20 \%$ of males were trolled in Instagram, $11 \%$ of females and $15 \%$ of males were trolled in Facebook, $17 \%$ of females and $29 \%$ of males were trolled in Twitter, and $3 \%$ of females and $5 \%$ of males were trolled in YouTube. Overall, $40 \%$ of males and $26 \%$ of females indicated being trolled at least once during the semester with a larger percentage of males versus females being trolled on each social media site except Linkedln and YikYak. In terms of the quantity of trolls received per student being trolled, the overall quantity for males and females was nearly identical, 17.8 and 17.7 per month per student, respectively. The volume, however, does vary by gender for each of the social media sites.

Finally, a correlation analysis of study factors suggests several relationships. Females were correlated to more minutes on social media while males were correlated to receiving a larger volume of trolls. In addition, the more minutes that one spent on social media was correlated to one receiving more trolls.

\section{Implications}

There are two important implications from these findings:

1. One implication is with respect to social media site usage. Gender appears to be a factor in the number of social media sites used and the minutes spent at a given site. Females used more social media web sites and were more actively involved with respect to time. It is possible that females value online socialization more than males or that males prefer face-to-face socialization. Or, females may have greater discretionary time and/or may have a greater addiction to social media than males. Another explanation is that females may be more socially conscious about celebrities, fashion, and so on, and thus need to scour a variety of social media sites for a longer time period to keep up-to-date. Further research will be needed to explore the antecedents or motivation for each student's social media behavior to determine if social media involvement is a positive component of the student's learning experience while in college. If it is demonstrated that this engagement is a detriment, females may then need additional pedagogical assistance in mitigating effects because of their increased involvement in social media.

2. A second implication relates to gender differences with respect to trolling. Chart 1 illustrates that for each of the five primary social media sites, a larger percent of males versus females were trolled. Chart 2 depicts the quantity of trolls received by gender for each of these sites. As a result, it is evident that while quantity varies by site, gender is a 
factor with males receiving more trolls. Further research is needed to explore why these gender differences occur. It is possible that males are more aggressive, assertive, or make more controversial statements in social media engagement and thus more likely to stimulate a trolling response. Or, males may be more forthright in reporting or may feel less shame about admitting he has been trolled. Given the relatively high percentage of students ( $40 \%$ of males and $26 \%$ of females) that are being trolled, it is likely that trolling education is either non-existent in the educational curriculum or ineffective. Moreover, these gender trolling differences suggest that this education may need to be targeted with greater effort aimed at males.

\section{Chart 1: Percent of Students Trolled}

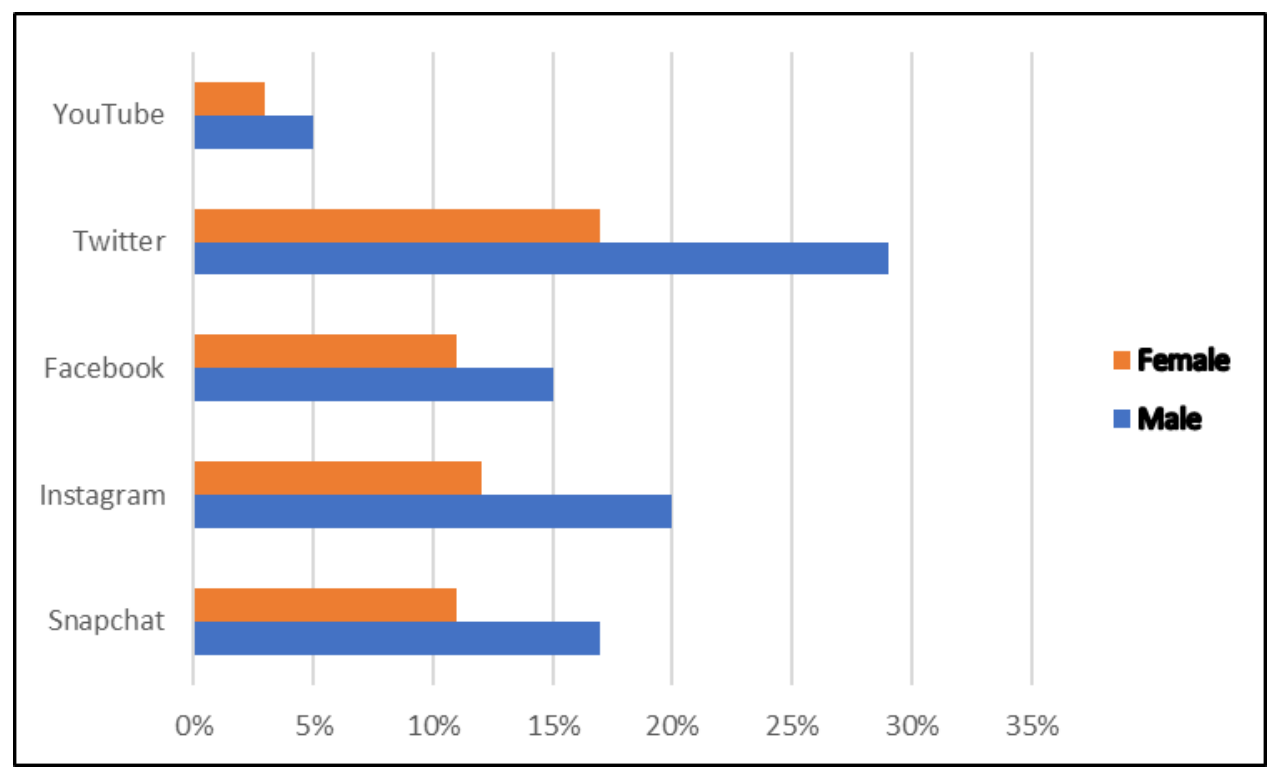

Source: Own based upon survey data

\section{Chart 2: Quantity of Trolls Received}

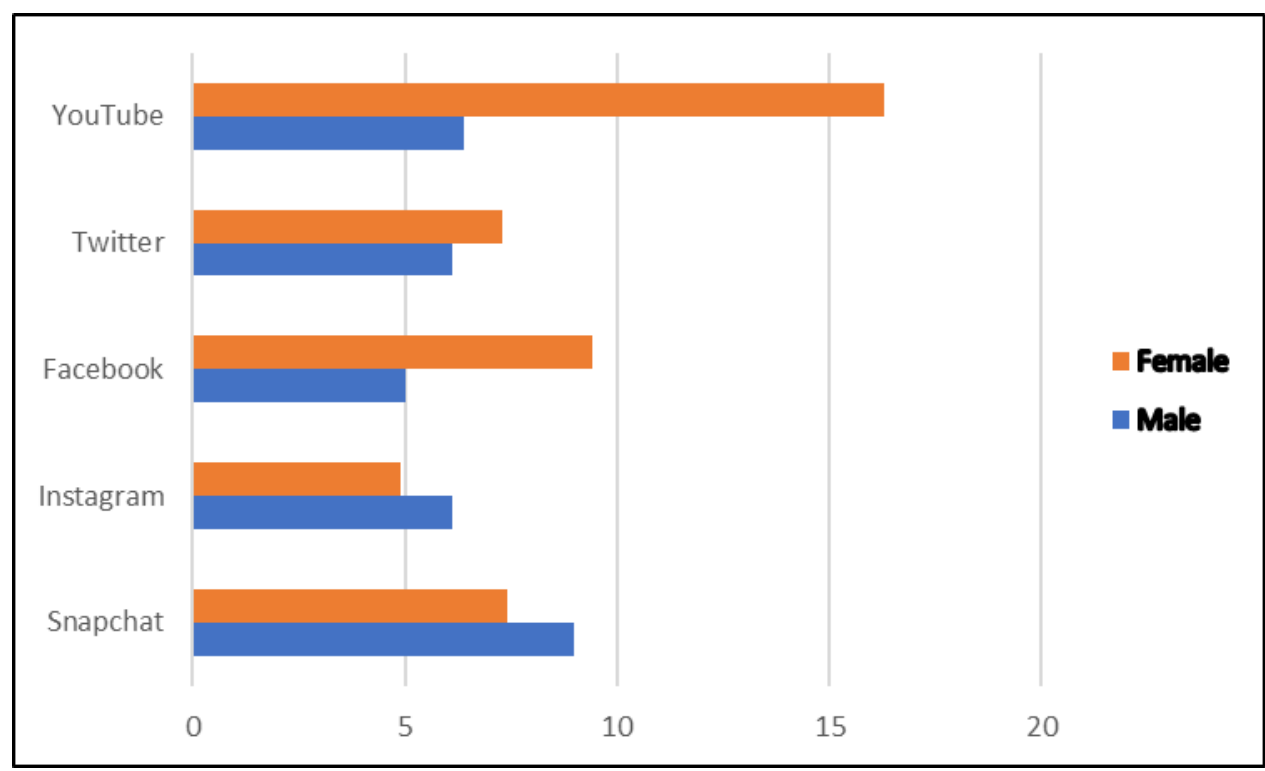

Source: Own based upon survey data 
The limitations of this study are primarily a function of the sample, sample distribution, and type of research. The use of additional universities and more equal distribution among academic class and gender would increase the robustness of results. Another limitation relates to the selfreported nature of the survey. Future research is needed to explore which measures in the education process may be most effective in promoting positive online social network behavior and effectively dealing with the receipt of troll comments. Overall, however, the study provides a profile and baseline to better understand undergraduate student social media usage and trolling.

\section{References}

ASLAM, S. (2019). Twitter by the Numbers: Stats, Demographics, and Fun Facts. omnicoreagency.com. January 16. Available: https://www.omnicoreagency.com/twitter-statistics/

BRADY, W. J., WILLS, J. A., JOST, J., TUCKER, J. A., \& VAN BAVEL, J. J. (2017). Emotion Shapes the Diffusion of Moralized Content in Social Networks. Proceedings of the National Academy of Sciences of the United States of America. July 11. Available: https://www.pnas.org/content/114/28/7313

CASE, C. J. \& KING, D. L. (2017). Internet Trolling in Social Networking Sites: A Preliminary Investigation of Undergraduate Student Victimization. Journal of Business and Behavioral Sciences. Vol. 29, No. 2, s. 32-43.

CHENG, J., BERNSTEIN, M., DANESCU-NICULESCU-MIZIL, C., \& LESKOVEC, J. (2017). Anyone Can Become a Troll: Causes of Trolling Behavior in Online Discussions. CSCW Conference Computer Support Coop Work. February-March, s. 1217-1230. Available: https://www.ncbi.nlm.nih.gov/pmc/articles/PMC5791909/

COOK, C., SCHAAFSMA, J., \& ANTHEUNIS, M. (2017). Under the Bridge: An In-Depth Examination of Online Trolling in the Gaming Context. Sagepub.com. December 28. Available: https://journals.sagepub.com/doi/full/10.1177/1461444817748578

EDWARDS, H. S. (2018). Washington Takes on the Threat of Big Tech. Time. September 17, Vol.192, No. 11, s. 22.

KATS, R. (2018). How Many People Are Using Snapchat? Emarketer.com. October 26. Available: https://www.emarketer.com/content/the-social-series-who-s-using-snapchat-infographic

KIRKPATRICK, D. (2018). The Facebook Defect. Time. April 3, Vol. 191, No. 15, s. $39-44$.

LAZARUS, D. (2019). Facebook is Laughing all the Way to the Bank as Americans Shrug Off Privacy Concerns. LATimes.com. February 4. Available: https://www.latimes.com/business/lazarus/la-filazarus-facebook-is-winning-the-privacy-war-20190204-story.html.

MERCHDOPE (2019). 37 Mind Blowing YouTube Facts, Figures and Statistics. MerchDope.com. February 22. Available: https://merchdope.com/youtube-stats/

ORTUTAY, B. \& SWEET, K. (2018). Twitter Suspended 58 Million Accounts in 4Q. Apnews.com. July 18. Available: https://www.apnews.com/1ee30b22a9ae4267a4e6e5f218bc625b

SCHLADEBECK, J. (2018). Thousands of Twitter Accounts Spreading Fake News During 2016 Election are Still Active - and Networks of Bots are Creating a 'Disinformation Supercluster'. 
NYDailyNews.com. October 4. Available https://www.nydailynews.com/news/national/ny-newstwitters-accounts-disinformation-campaign-remain-active-20181004-story.html

SEST, N. \& MARCH, E. (2017). Constructing the Cyber-Troll: Psychopathy, Sadism, and Empathy. Personality and Individual Differences. December, Vol. 119, No. 1, s. 69-72. Available: https://www.sciencedirect.com/science/article/pii/S0191886917304270

SHIEBER, J. (2019). 2018 Was More of a Dumpster Fire for Online Hate and Harassment, ADL Study Finds. techcrunch.com. February 13. Available: https://techcrunch.com/2019/02/13/2018-reallywas-more-of-a-dumpster-fire-for-online-hate-and-harassment-adl-study-finds/

STATISTA (2019). Number of Monthly Active Instagram Users from January 2013 to June 2018. Statista.com. February 22. Available: https://www.statista.com/statistics/253577/number-ofmonthly-active-instagram-users/

STEINMETZ, K. (2018). Real News the Fake Crisis. Time. August 20, Vol. 192, No. 7, s. 26-31.

WEBSTER, M. (2019). Troll. merriam-webster.com. Available: https://www.merriamwebster.com/dictionary/troll

YOUTUBE (2019). YouTube For Press. YouTube.com. February 22. Available:

https://www.youtube.com/yt/about/press/ 